\title{
Documento autobiográfico: costuras estéticas nos processos narrativos da prática docente
}

\author{
Autobiographical document: aesthetic seams in the \\ narrative processes of teaching practice
}

Documento autobiográfico: costuras estéticas en los procesos narrativos de la práctica docente

\author{
Margaréte May BeRKenBRock Rosito (Da \\ Juliana Paiva Pereira De Souza ${ }^{1} b$
}

\section{Resumo}

Este artigo tem como objeto de estudo a tomada de consciência estética das experiências subjetivas para constituição da identidade docente. Tem como objetivo compreender o sentido da dimensão estética nas narrativas autobiográficas dos discentes que participaram do dispositivo "Colcha de Retalhos" na disciplina "Organização do trabalho docente", no primeiro semestre de 2018, do curso de Pedagogia, de uma Universidade privada, localizada na zona leste da cidade de São Paulo. Adota-se o conceito de estética de Schiller (2002), entre sensível e a razão; de Adorno (2002), o de emancipação; de Josso (2006), narrativas autobiográficas; e de Freire (2013), o de autonomia, considerando a articulação entre consciência estética e consciência epistemológica. Neste estudo, compreende-se o dispositivo "Colcha de Retalhos", como metodologia e epistemologia de formação e investigação. A interpretação das narrativas, sob o enfoque hermenêutico, em Gadamer (2000), apresenta uma contribuição para a prática de formação estética dos professores, visando à percepção da constituição da identidade

\footnotetext{
a Universidade Cidade de São Paulo, São Paulo, SP, Brasil. Doutorado em Educação/UNICID, email: margaretemay@uol.com.br

b Universidade Cidade de São Paulo, São Paulo, SP, Brasil. Mestrado em Educação, e-mail: julianappereira@hotmail.com
} 
docente por meio das experiências subjetivas, através de narrativas de situações pessoais e escolares relacionadas diretamente ao gosto e desgosto que se constituem como núcleo fundante na constituição estética da prática docente.

Palavras-chave: Narrativas. Prática Docente. Experiência Estética.

\begin{abstract}
This article aims to study the aesthetic awareness of subjective experiences for the constitution of the teaching identity. It aims to understand the meaning of the aesthetic dimension in the autobiographical narratives of the students who participated in the device "Quilt" in the discipline "Organization of teaching work", in the first semester of 2018, of the Education course, of a private University, located in east side of the city of São Paulo. Schiller's (2002) concept of aesthetics is adopted, between sensitive and reason; Adorno (2002), emancipation; Josso (2006), autobiographical narratives; and Freire (2010), autonomy, considering the articulation between aesthetic and epistemological awareness. In this study, we understand the device "Quilt", as a methodology and epistemology of training and research. The interpretation of narratives, under the hermeneutic approach, in Gadamer (2000), makes a contribution to the practice of aesthetic training of teachers, aiming the perception of the constitution of the teaching identity through subjective experiences through narratives of personal and school situations directly related to the taste and disgust that constitute the founding nucleus in the aesthetic constitution of teaching practice.
\end{abstract}

Keywords: Narratives. Teaching Practice. Aesthetic Experience.

\title{
Resumen
}

Este artículo tiene como objetivo estudiar la conciencia estética de las experiencias subjetivas para la constitución de la identidad docente. Su objetivo es comprender el sentido de la dimensión estética en las narraciones autobiográficas de los estudiantes que participaron en el dispositivo "Colcha de Retazos" en la disciplina "Organización del trabajo docente", en el primer semestre de 2018, del curso de Pedagogía, de una universidad privada, ubicada en lado este de la ciudad de São Paulo. Se adopta el concepto de estética de Schiller (2002), entre sensible y razón; Adorno (2002), el de la emancipación; de Josso (2006), narraciones autobiográficas; y Freire (2010), el de autonomía, considerando la articulación entre la conciencia estética y epistemológica. En este estudio, entendemos el dispositivo "Colcha de Retazos", como metodología y epistemología de capacitación e investigación. La interpretación de las narrativas, bajo el enfoque hermenéutico, en Gadamer (2000), contribuye a la práctica de la formación estética de los docentes, apuntando a la percepción de la constitución de la identidad docente a través de experiencias subjetivas por medio de narrativas de situaciones personales y escolares, directamente relacionadas con el gusto y el asco que constituyen el núcleo fundador de la constitución estética de la práctica docente.

Palabras clave: Narrativas. Práctica docente. Experiencia estética. 


\section{Introdução}

Este artigo tem como foco o objeto material constituído por 46 narrativas produzidas por meio do dispositivo "Colcha de Retalhos" por discentes que cursavam o segundo semestre do Curso de Pedagogia, no ano de 2018, participantes da disciplina "Organização do Trabalho Docente", com vistas a observar a tomada de consciência de experiências subjetivas para (re) significação da identidade docente. Para esta observação, se tomará como base a afirmação de que o desenvolvimento da autonomia e emancipação dos sujeitos ocorre via a dimensão estética na Educação.

Freire (1996) explana como a autonomia pode ser desenvolvida. Isso ocorre por meio de um processo em que o sujeito é suscitado a fazer escolhas e a tomar decisões. A possibilidade de escolha está em o que revelar e o que guardar para si, abre-se espaço que envolvem a sua criatividade, considerando no exercício da prática docente o conhecimento de mundo que o discente traz.

As narrativas em suas dimensões escrita, pictórica e oral, produzidas por participantes da "Colcha de Retalhos" são tratadas como Documento Autobiográfico que permite a investigação de aspectos significativos para a ampliação da compreensão sobre a formação de professores e pesquisadores. A narrativa é construída por histórias individuais e coletivas, ou, a singularidade das histórias construídas no coletivo; a partir de um olhar particular, a produção dessas narrativas se transforma em Documento Autobiográfico.

Neste artigo, buscou-se compreender a Educação Estética como lugar de relevância na produção de narrativas autobiográficas, pois compete a ela o despertar da sensibilidade, que apresenta um universo de emoções, tratadas como questões epistemológicas, suscitando aos sujeitos a capacidade de elaborar e recriar o que já sabe, transformando sua realidade.

A narrativa (Auto)Biográfica é refletida como dimensão estética por meio de um diálogo entre sensível e razão, vestígios primeiros constituintes da trajetória existencial, na relação tempo e espaço. Assim, Freire (1996) sinaliza a perspectiva existencialista, como problematizadora que pressupõe a mudança, a esperança, considerando a historicidade própria dos sujeitos, capazes de caminhar para frente em contraposição ao determinismo científico, cultural e histórico. 
A estética, para Schiller (2002), seria como um jogo entre o sensível e a razão, ele ressalta que o sensível emerge por meio do arrebatamento ou sensação de epifania, tudo que nos atinge, nos afeta, sem pedir permissão, que se manifesta pelo gosto ou não gosto, sobre o que lemos, vemos, ouvimos, tocamos, contemplamos e como reagimos, ora com paixão, ora com repulsa ou desinteresse, porém, o autor ressalta que embora o sensível e razão são ao mesmo tempo dependentes e independentes, na dimensão sensível revela-se uma dimensão da razão, atrelada à moral, na forma dos valores, das regras e leis de uma sociedade.

A Educação Estética é uma educação para o sentir, figurada nas relações de gosto e desgosto, belo e feio existentes em todas as relações e experiências. Nesta perspectiva, afirma Santos (2009) que, em Schiller (2002), a dimensão estética se manifesta na Educação por meio do projeto pedagógico, ou seja, no próprio conteúdo da educação, na finalidade da educação, na forma de educar, bem como no espírito da educação e no ambiente que envolve o processo educativo e formativo: mobiliário, arquitetura do prédio, paisagem urbanística, relações entre as pessoas e, por fim, a Educação Estética também como educação para a arte e pela arte.

Schiller (2002), Adorno (2002) e Freire (1996; 2013), ao destacarem a importância da dimensão estética na educação e na prática docente, convergem no sentido de entender a relação entre sensível e razão, em contraposição à hegemonia dos processos de racionalização tão evidenciada, especialmente, na produção de conhecimento, no Ocidente: onde ocorre sua difusão, sua interpenetração, seu aceleramento, que procura explicar o sentido do universo quase que exclusivamente através da razão, há o desprezo da metafísica, privilegiando o conhecimento experimental da realidade. O conhecimento do real se dá através de uma atitude eminentemente racionalista/ racionalidade instrumental. Adorno (2002) apregoa que a tarefa do homem é emancipar-se da racionalidade instrumental, que forja a estética da massificação cultural, conduzindo os indivíduos a serem excessivamente práticos e irreflexivos na busca de atender à reprodução de conhecimentos.

A dimensão estética na prática docente é esse tempo menos veloz, abre-se espaços para criar a narrativa de sua história, que se compreende como um sujeito existencial, percebendo-se como ser humano, capaz de compor e entender sua visão de mundo na própria história de vida. Nesse sentido, a narrativa (Auto)Biográfica 
transita entre: sensível e razão, conhecimento e senso comum, conceito e imagem, singular e coletivo, arte e ciência, vida e morte, estas categorias que estão presentes no exercício da educação e na vivência e convivência social na prática docente.

Sendo assim, para Josso (2007), o ato de narrar "através da análise e da interpretação das histórias de vida escritas, permite colocar em evidência a pluralidade, fragilidade e a mobilidade de nossas identidades ao longo da vida" (JOSSO, 2007, p. 415).

Adorno (2002) destaca como o reconhecimento do sujeito constituído socialmente é importante, pois o ato de narrar possibilita a identificação de momentos cruciais na vida de quem narra, com destaques para situações junto à família e outros grupos sociais, que foram fundamentais para a constituição das histórias.

Com Winnicott (1999), o olhar da Psicologia que ajudará a compreender a importância de um ambiente que favoreça a constituição do indivíduo considerando fundamentalmente as relações estabelecidas, objetivando a autonomia e emancipação do sujeito. Nessa perspectiva, enfatiza-se o sujeito e suas circunstâncias, a subjetividade como fonte legítima de produção de conhecimento, não abrindo mão da formação científica, atenta aos movimentos da inclusão da arte como dimensão estética e política presente na análise de sentido e na possibilidade seus significados, e formação do profissional.

Encontram-se os eixos que foram extraídos das narrativas escritas dos quarenta e seis alunos do Curso de Pedagogia sobre a sua participação na "Colcha de Retalhos" como um dispositivo que possibilita o encontro com o sensível que habita cada ser. Para a análise do material produzido, recorremos ao referencial teórico apresentado anteriormente.

\section{Metodologia: a "Colcha de Retalhos" como dispositivo de formação e investigação}

A “Colcha de Retalhos” foi uma proposta dos alunos para Berkenbrock-Rosito (2009), em 2001, a partir do filme Colcha de Retalhos. A partir do momento em que se aceitou a inserção da proposta dos alunos em sua prática docente, no curso de Pedagogia, todos os momentos narrativos que serão descritos foram emergindo a 
cada vivência com os alunos na elaboração da "Colcha de Retalhos". Por meio de suas avaliações e propostas foi incorporando e estruturando este procedimento.

A "Colcha de Retalhos" proporciona diferentes processos narrativos: narrativas biográficas, autobiográficas, fílmica, oral e pictórica como um fenômeno antropológico educacional, método de pesquisa e como dispositivo pedagógico de formação inicial e continuada de professores.

As narrativas são produzidas na participação da "Colcha de Retalhos", dispositivo desenvolvido por Berkenbrock-Rosito (2009), fundamentado na concepção de que o desenvolvimento da autonomia e emancipação dos sujeitos se dá por meio da narrativa e da reflexão acerca da dimensão estética de sua trajetória formativa, organizada em três dimensões: escrita, pictórica e oral, compostas por etapas e alcançadas por determinadas estratégias.

Na primeira dimensão, a escrita, os participantes são convidados a descrever três cenas marcantes de sua experiência na educação básica: no Ensino Médio, se aluno da graduação, se aluno do Mestrado em Educação e Mestrado Profissional Formação de Gestores Educacionais, as cenas advindas da Educação Superior. Para tanto, tem-se como estratégia o uso de três perguntas, com o objetivo de refletir sobre a relação com o conhecimento: Que tipo de aluno foi? Qual a relação com o professor? Esta relação era de autoria ou submissão?

A segunda etapa da narrativa escrita é a elaboração do quadro "Linha da vida". Neste momento, os participantes devem por meio de categorias de tempo e espaço, vida familiar, vida escolar, vida profissional, vida acadêmica, pessoas, livros, filmes, que influenciaram deslocamentos geográficos, vida amorosa, entre outras categorias de espaço, realizar um mapeamento de momentos charneiras. Esses momentos charneiras significam momentos marcantes que funcionam como divisores de água, em que há uma mudança de referencial de vida. Desta forma, busca-se compreender como o sujeito conhece e qual o impacto das aprendizagens na formação social, profissional e pessoal.

$\mathrm{Na}$ terceira etapa, os participantes assistem ao filme Colcha de Retalhos (How to make an American quilt, de Mocelin Moorhouse, EUA, 1995) com o objetivo de buscar metáforas significativas da sua história de vida, compondo assim a etapa da narrativa fílmica, ainda dentro da dimensão escrita. 
Em seguida, passamos à outra dimensão que é a narrativa pictórica, construída a partir da narrativa escrita. Na primeira etapa, os participantes buscam imagens e metáforas nos relatos escritos, para que, através da estratégia da confecção do retalho, possam montar imageticamente sua narrativa, para compor com todos os participantes um produto final único. Nesta dimensão, também consideramos os registros fotográficos realizados após a exposição da colcha pronta.

Por fim, entramos na dimensão da narrativa oral. Em roda, cada participante conta a sua história. Depois de contar a sua história e ouvir a história do outro, ocorre a costura coletiva dos retalhos, formando a colcha e, depois de formada, apreciação estética da obra "Colcha de Retalhos", trazendo também as impressões e discussões acerca da construção coletiva.

Vale reafirmar que os conteúdos a serem apresentados na narrativa passam por um processo de escolha, por parte do narrador, do que será transmitido. Josso (2006) nos chama atenção para isto, esclarecendo que: "cada narrador tem consigo mesmo ao longo do processo de pesquisa-formação a fim de decidir o que ele deseja partilhar e o que ele prefere guardar consigo" (JOSSO, 2006, p. 376)

As narrativas desenvolvidas no dispositivo "Colcha de Retalhos" são tratadas como Documento Autobiográfico, para um processo de reflexão da escrita, da oralidade e do desenho de si consciente de um futuro docente.

A análise documental é utilizada como procedimento para análise da documentação composta pelas 46 narrativas. Para organização dos dados, utilizamos a Análise Temática proposta por Jovchelovitch e Bauer (2002). Neste tipo de análise, os dados são transpostos para um quadro, no qual na primeira linha consta o nome fictício do narrador; na segunda linha, o texto principal na íntegra; na terceira linha, a paráfrase; na quarta linha estão as palavras-chave e por último, na quinta linha, a categoria ou eixo. A paráfrase é obtida com o processo gradual de redução do texto qualitativo, até que se chegue a uma sentença sintética de passagens inteiras ou parágrafos. As palavras-chaves são advindas da paráfrase e as categorias ou eixos são incorporados ao processo com o objetivo de facilitar a discussão dos resultados encontrados.

Os dados extraídos das narrativas foram interpretados à luz da Hermenêutica na perspectiva de Gadamer (2000). O enfoque hermenêutico trata da compreensão 
do pensamento do outro e do mundo, e consequentemente a compreensão de si, um modo de linguagem. Neste sentido, “compreender significa que eu posso pensar e ponderar o que o outro pensa. [...] Compreender não é, portanto, uma dominação do que nos está à frente, do outro e, em geral, do mundo objetivo” (GADAMER, 2000, p. 23).

O autor ainda ressalta que: "quem pretende compreender está exposto a confundir-se pelas opiniões prévias que não estão adequadas às coisas mesmas" (GADAMER, 2000, p. 144). Logo, o saber da experiência é constituído a partir do lugar do outro, o autor entende como lugar do jogo nas experiências vivenciadas, pois "o saber gerado pela experiência hermenêutica abraça as próprias pessoas, a sua história, o seu saber prévio, seus preconceitos e suas expectativas" (GADAMER, 2000, p. 42).

Delory-Momberger (2014) explana que o trabalho com narrativa possibilita olhar para os processos que biografizamos, das situações e acontecimentos que damos forma e significado para converter em experiências que são escritas e analisadas. Assim, é de extrema relevância considerar os sentidos ali explícitos e implícitos na construção das narrativas, considerando que o conteúdo apresentado dependerá dos sujeitos envolvidos, suas convicções, valores e histórias de vivenciadas até aquele momento.

Assim, vamos fazer um recorte na apresentação da análise dos dados ${ }^{1}$. O foco será na dimensão escrita da narrativa, sobre o que dizem os discentes sobre a sua relação com o conhecimento com o professor, se foi uma relação de autonomia ou submissão.

Além disso, analisaremos os momentos charneiras que funcionaram como divisor de águas em sua trajetória formativa dentro e fora do espaço escolar. As narrativas acabam por revelar uma determinada cultura e o poder de transformar esta realidade. Isto ocorre porque no momento em que narram suas histórias, os sujeitos são obrigados a revisitá-las, questionando realidades antes tidas como certas.

\footnotetext{
${ }^{1}$ Para apresentação das narrativas produzidas, utilizaremos nomes das pontes, evitando assim uma possível identificação dos sujeitos participantes da pesquisa. Não escolhemos nomes de pontes exclusivamente brasileiras, pois muitas estão associadas ao período da ditadura, período da história de privação de direitos em que a autonomia e emancipação eram tidos como um perigo para a sociedade.
} 


\section{Narrativa escrita: relação com o conhecimento, 0 professor e a linha da vida, entre autonomia e a submissão}

Este caminho percorrido ao relatar momentos marcantes vividos no Ensino Médio, as lembranças das relações estabelecidas com os professores e com o conhecimento podem ser fundantes na constituição da estética da identidade e do trabalho docente: o desenvolvimento da autonomia.

Neste momento inicial, abordaremos os dados quantitativos e qualitativos relacionados às perguntas: qual sua relação com o professor e o conhecimento? Foi de autoria ou submissão?

Tabela 1 - Relação com professor e com o conhecimento

\begin{tabular}{l|c|c|c|} 
& Submissão & Autoria & Não respondeu \\
\hline Relação com o professor & $64 \%$ & $31 \%$ & $5 \%$ \\
\cline { 2 - 4 } Relação com o conhecimento & $68 \%$ & $25 \%$ & $7 \%$ \\
\hline
\end{tabular}

Fonte: Elaborado pelas pesquisadoras.

Neste contexto, temos um número expressivo de alunas caracterizando suas vivências como de submissão, seja com o professor ou com o conhecimento, num determinado momento da vida escolar.

É sabido que a aprendizagem mobiliza no sujeito uma série de recursos internos e externos, deixando marcas por um longo período no sujeito. Assim, podemos afirmar que as experiências estéticas vivenciadas no ambiente escolar são de fundamental importância para formação do futuro professor, principalmente no que tange à possibilidade de assumir uma postura de autoria com relação à construção de seu conhecimento, percebendo-se como sujeito da ação.

Quando as alunas identificam que estabeleceram uma relação de submissão com os professores, conseguimos identificar o que Freire (2005) destaca como situação de violência instaurada. A opressão vivenciada nos anos escolares está impregnada na historicidade destas alunas, como podemos observar nos relatos abaixo. 
Submissão, lembro que ao errar a tabuada eles usavam a palmatória (Ponte Suspensa).

Em relação aos professores encontrei poucos que realmente amavam a profissão e que estivessem dispostos a se aprofundar no aluno, era muita cópia e poucas discussões, pouco envolvimento, era uma relação totalmente submissa (Ponte Gateshead Millennium).

Considerando este cenário, podemos nos remeter a Freire (2005), quando ele esclarece que quando instaurada uma situação de opressão e, por conseguinte, de violência, isto suscita "gera toda uma forma de ser e comportar-se nos que estão envolvidos nela. Nos opressores e nos oprimidos. Uns e outros, porque concretamente banhados nesta situação, refletem a opressão que os marca" (FREIRE, 2005, p. 50).

Ao narrar sua trajetória educacional, os participantes tiveram a possibilidade de entrar em contato com o "professor ideal / professor idealizado" e com isto ressignificar sua história. Adorno (2002) esclarece que: as pessoas com consciência coisificadas são "apegadas" à técnica e o quanto isto acaba sendo limitante na existência humana. Relacionando com a constituição da identidade do trabalho docente, podemos ter aquele professor que domina as técnicas em sala, porém não constrói nenhuma relação com o aluno, desconsiderando sua existência, desejos, angústias e anseios.

No relato a seguir é possível perceber o quanto relações estabelecidas desta maneira deixam marcas que podem prejudicar o indivíduo por um longo período: “ $O$ vínculo com o professor era muito complicado, falava "eu ensino e você aprende, não podia ficar perguntando muito, pois logo tinha resposta inadequada (Ponte Kawazu).

Importante destacar o lugar que o professor ocupa historicamente: lugar de poder e de detentor do saber. Ao trabalhar com narrativas de vida, é possível perceber que em muitas histórias este lugar ainda é de destaque, sempre surge um relato de um professor que utilizava do seu saber e de seu poder para submeter os alunos a situações conflitantes e desagradáveis, mostrando-se muitas vezes desrespeitoso e violento.

Outro aspecto a ser observado com atenção, diz respeito ao entendimento distorcido que o medo e a punição dará controle ao professor e o quanto alguns, ou a grande maioria, têm este entendimento. Haja vista os relatos apontados pelas alunas: 
Minha relação com o conhecimento foi um pouco difícil, porque tinha algumas dificuldades na aprendizagem, porém tinha muito medo de fazer perguntas, pelo fato de algumas professoras serem muito enérgicas (Ponte Amgen).

A relação com o professor não tinha muita opção, pois era sempre com cópias em cima de cópias, trabalhos e atividades do jeito que eles pediam. Sempre uma relação de submissão (Ponte Hangzhou).

Aprendi que não devo ficar perguntando por quê. Nem todo mundo gosta de ficar respondendo suas dúvidas, apesar de estar lá para isso (Ponte Forte-Redinha).

A busca por uma educação que liberte os sujeitos, que possam se perceber como autônomos e capazes de escolher, conseguem ser validados pelas narrativas a seguir:

A minha relação com o conhecimento no início foi bem complicada devido as dificuldades que eu me acarretei por falta de conteúdos no ensino fundamental. Porém, ao longo do tempo com o auxílio de professores essa relação se tornou simples e não se tornou uma relação de submissão e sim de autoria (Ponte Alamillo).

O primeiro momento foi quando uma professora de português disse para a sala que todos aprendem, que ela acreditava no potencial de cada um pois todos eram capazes, que ela acreditava em todos e não iria desistir. Achava legal pois ela sempre incentiva e ajudava a todos (Ponte Sporenburg).

Neste contexto, podemos compreender como a sala de aula pode virar um território de desejos confusos e desorientados e, neste momento, o papel do professor faz toda a diferença.

Como vimos, os dados indicam que as relações estabelecidas foram focadas em processo de submissão. Contudo, tivemos situações em que os professores atuaram como mediadores entre os alunos e o conhecimento, auxiliando no processo de construção dos saberes. Os relatos abaixo possibilitam esta associação.

Primeiro ano tive um professor que ensinava filosofia, ele sabia como dizer as palavras de forma que criasse em mim a vontade de me aprofundar sobre cada assunto. Ele enxergava as coisas de forma diferente, ele nos ensinou o valor da sabedoria e que sonhar é o combustível para viver nesse mundo (Ponte Webb).

Professor de história que era o máximo a aula dele, ele trazia a matéria para a nossa realidade, ficava muito mais fácil para compreender a matéria (Ponte Conwy).

A aula de sociologia nos fazia ter discussões construtivas em sala de aula, onde podíamos colocar o que pensávamos para aquela época de uma forma juvenil e imatura posso dizer assim (Ponte Astoria). 
Cabe destacar como é essencial que o professor considere o que o aluno possui de conhecimento e vivência, para que possa partir deste ponto para estabelecer relações de tal modo que qualquer conteúdo passe a fazer sentido e seja significativo.

Quando trabalhamos com o conceito de momento charneira buscamos compreender quais foram os momentos da vida que contribuíram para constituição do indivíduo. Considerando que estes aspectos estão diretamente relacionados com a maneira como ele conduz sua maneira de aprender, seja no mundo escolar/acadêmico, seja nas relações interpessoais cotidianas.

No momento em que realizamos o levantamento dos aspectos que mais marcaram os sujeitos participantes desta pesquisa, foi possível notar a constituição de um tripé: família, escola e religião. A família é sempre apontada em dois caminhos: a que promove e incentiva o desenvolvimento ou a que colabora para reforçar no sujeito sua incapacidade de fazer algo produtivo em sua jornada. Com isso, pode-se ressaltar que essas instituições também atrapalham ou muitas vezes impossibilitam o desenvolvimento dos sujeitos.

Os depoimentos apresentados pelas alunas a seguir, possibilitam compreender o quanto o ambiente familiar pode ser um caminho de desintegração do sujeito e, consequentemente, comprometer a maneira como este futuro professor pode compreender a influência do seu papel na vida daqueles que se propuser a desenvolver.

\begin{abstract}
Meu pai sempre foi uma pessoa difícil de lidar devido aos vícios da bebida e do cigarro, vivia nos ofendendo, minha mãe era quem mais sofria. Minha mãe saía para trabalhar e meu pai ficava nos humilhando, quando minha mãe chegava ainda ficava a ameaçando e dizendo coisas horríveis (Ponte Beipanjiang).
\end{abstract}

Já recebi apelidos maldosos da minha familia com a justificativa de que era para uma melhora, algumas vezes encontrei até comida escondida, confesso que já até tentei tirar minha própria vida, não era fácil passar por tudo aquilo (Ponte Sporenburg).

Maturana (1998) nos lembra de que aquele que obedece passa a negar a si mesmo, pois, para evitar ou ter algo, faz o que não quer porque o outro pediu. Apesar de as paráfrases não falarem diretamente sobre a obediência, está implícito o lugar que ela ocupa nos cenários apontados. As alunas indicam situações em que muitas vezes não puderam expor o que realmente desejavam para atender uma demanda externa ao desejo delas. A necessidade de compreender estes aspectos é essencial para 
que no momento da sua prática, este futuro professor não reproduza as opressões sofridas.

Em alguns momentos, como os presentes nos relatos apresentados anteriormente, se dá quase um apagamento do sujeito, que terá sua identidade afetada por esta experiência, uma vez que "a identidade individual é, pois, definida a partir de características sociais, culturais, políticas, econômicas, religiosas, em termos de reprodução sociofamiliar e socioeducativa” (JOSSO, 2007, p. 417).

Já a aluna Kawazu relata o quanto a dificuldade de alguns membros da família em permanecer na escola foi fator de incentivo para que ela não desistisse da jornada e procurasse cada vez mais investir em sua formação.

Naquele momento eu refleti e fiquei muito triste, percebi o quanto era difícil de quem não sabia ler, meus pais são analfabetos funcionais, o pai era pedreiro, calçava as ruas então enfrentando toda a dificuldade financeira eu não podia parar de estudar para trabalhar, já tinha histórico na familia de abandono escolar e eu não quis repetir o mesmo erro (Ponte Kawazu).

É possível corroborar as marcas registradas no corpo e na alma, por exemplo, com os relatos apresentados pela aluna a seguir:

No sexto ano eu tinha uma professora muito especial, ela lecionava português, lembro até hoje o nome dela: Alessandra. Eu era muito esperta em português, compreendia com muita rapidez a matéria e por isso ela me colocou para liderar um grupo de estudos para os alunos que estavam com dificuldade em português (Ponte Henderson Wave).

Conseguimos perceber nestas paráfrases o quanto o papel do professor mobilizou no outro o desejo em aprender e, com isto, desenvolver um sentimento de pertença apropriado. Estes momentos charneiras criaram a condição para um repertório do fazer profissional docente comprometido, validando o direito de existir mesmo num cenário por vezes conturbado.

Nesta perspectiva, Tardif (2002) ressalta que ao lembrar-se de suas experiências no período escolar, o professor buscará em seu repertório as vivências com os professores de personalidade marcantes. Ele relata ainda que a constituição da identidade docente é composta pelas experiências vividas pelo indivíduo, e que estas permitem uma ressignificação de fatos passados para uma estruturação diferenciada do futuro, considerando sempre valores, normas e tradições envolvidas em cada história. 
Meu grande divisor de águas foi conhecer a Jesus, agradeço a ele da pessoa que me tornei hoje, com defeitos, pecados, mas com a certeza de que podemos sempre fazer a diferença moldando nosso caráter para servir quem sempre nos serviu (Ponte Orinoquia).

A proposição de pensar o lugar dado à religião relaciona-se ao que no decorrer deste estudo propomos dialogar: autonomia e emancipação do sujeito via dimensão estética. Neste viés, o questionamento que surge está relacionado justamente ao lugar de responsabilidade dado à religião, pois é ela quem, de acordo com as paráfrases selecionadas, decide qual o caminho que o sujeito deve seguir e como deve fazê-lo. Ao mesmo tempo em que ela pode ser fonte de inspiração e proporcionar ao sujeito a sensação de integralidade, ela também tem o poder de cercear os caminhos possíveis para autonomia.

Neste contexto, Winnicott (1983) aponta o quanto precisamos ficar atentos nestes aspectos, pois ao trazer a religião como fio condutor das ações, existe o esvaziamento da criatividade individual do indivíduo. Este processo de esvaziamento da criatividade pode vir a afetar o processo de amadurecimento, e consequentemente comprometer a ação deste futuro professor em sala, porque suas ações estarão pautadas neste tipo de experiência.

Pensar os aspectos que envolvem a prática docente pode favorecer a possível ressignificação dos papéis desempenhados até o momento na jornada formativa. Neste mesmo sentido, Passegi (2013, p. 13) nos lembra que

o professor deve ter disponibilidade para percorrer, com a pessoa em formação, múltiplos e árduos caminhos, a começar pela imersão na escrita de si, que solicita, no processo de biografização, operações de linguagem, envolvendo a reflexão sobre a busca da historicidade de si e das aprendizagens no percurso intelectual e profissional, o que implica reinventar-se como autor de um texto autobiográfico.

Frente a isto, podemos inferir que a experiência vivenciada através do dispositivo "Colcha de Retalhos", permite aos participantes o que Delory-Momberger (2016) denomina de escrita de vida. A autora ressalta a importância de compreender como cada sujeito, no processo da narrativa, vincula a experiência vivida com sua própria história. Neste sentido, considerar o contexto espaço/tempo, contexto intelectual, cognitivo, social, familiar, doméstico, psicológico e afetivo, histórico e geográfico é fundamental para compreender os aspectos constitutivos do sujeito. 
Estas experiências permitem aos envolvidos passar por um processo de aceitação de si e de sua história. Maturana (1998) defende que "sem a aceitação e respeito por si mesmo não se pode aceitar e respeitar o outro, e sem aceitar o outro como legítimo outro na convivência, não há fenômeno social" (MATURANA, 1998, p. 31).

O processo de escrita permite ao indivíduo o desvelar de sua história e, com isto, propiciar o encontro com o que há de mais autêntico. Ao conhecer a história, existe a possibilidade de compreender os caminhos utilizados para aprender e com isto ressignificar o que até o momento era desconhecido.

A consciência desta autonomia, em sua grande maioria, é conflituosa e consideravelmente difícil. Olhar para história de si acaba por ser algo libertador, permitindo ao sujeito uma compreensão ampliada dos fatos.

Winnicott (1999) retrata a relação estabelecida entre o bebê/criança com sua mãe e consequentemente as influências desta relação na formação psíquica. Desta forma, ao narrar suas histórias de vida, as alunas revivem momentos e relações estabelecidas que permitem uma aproximação com a teoria em questão. $\mathrm{O}$ autor retrata que na relação mãe/bebê, a progenitora "traz com ela as lembranças [...] recordações de que alguém cuidou dela, e estas lembranças tanto podem ajudá-la quanto atrapalhá-la em sua própria experiência como mãe" (WINNICOTT, 1999, p. 4).

As alunas podem, ao olhar para seu percurso via experiência estética, identificar quais são as ações e/ou fatos podem vir a ressoar em seu fazer pedagógico. Como Freire (1996) diz, somos seres históricos e esta historicidade tem uma influência direta na maneira como o ser se relaciona com o saber e consequentemente na forma como facilitará o aprendizado para seus alunos.

Josso (2010) destaca como estes aspectos são fundamentais para o sujeito que narra e as implicações subjetivas envolvidas

embora se trate do distanciamento em relação ao coletivo, da capacidade de cooperação com os outros ou da superação das submissões emocionais e afetivas, as tomadas de consciência de suas limitações dinamizam o processo de formação de uma pessoa na qual a dialética entre vida interior (consciente e inconsciente) e interações (escolhidas ou impostas) com seu ambiente humano e natural serve de marco para a regulação dos conflitos ou tensões entre desenvolvimento individuado e conformação com as exigências socioculturais (JOSSO, 2010, p. 50). 
A autora pontua o papel decisivo do aprendente. A ação dele fará toda diferença na feitura da colcha, o gosto ou desgosto a partir desta experiência desencadeia uma série de lembranças, sensações e consequentemente sentimentos. Caso o aprendente esteja atento a todo este processo ele terá em mãos uma grande possibilidade de ressignificar e consequentemente transformar seu fazer docente. Com isso, podemos dizer que o uso de narrativas na formação inicial é um processo de desenvolvimento à autonomia do indivíduo, pois ela possibilita ao sujeito dar-se conta dos aspectos que constituem sua maneira de ser e atuar no mundo.

Nesta perspectiva, os alunos necessitam de "um meio ambiente firme, onde possam resolver seus conflitos de amor e ódio" (WINNICOTT, 1999, p. 8) e com isto ressignificar suas relações e favorecer a aprendizagem. Criar o que o autor chama de ambiente facilitador é justamente oferecer este espaço de ressignificação e autonomia. Assim, compreender a importância das narrativas escritas na "Colcha de Retalhos" é fundamental, pois traz contribuições relevantes para o estudo desta temática. Afinal, as narrativas contemplam o papel pesquisa formação. O processo de narrar sobre si é formativo e pode possibilitar a consciência da identidade docente, constituída em momentos que ocorrem na escola e fora dela.

A concepção do ambiente escolar, seja como um espaço de felicidade, com momentos bons ou como espaço de sofrimento e inexistência, surgiram nos relatos das alunas. Muitas vezes, a vivência pode vir carregada de situações de submissão, por não haver amor, pois, “o central na convivência humana é o amor, as ações que constituem o outro como um legítimo outro na realização do ser social que tanto vive na aceitação e respeito por si mesmo quanto na aceitação e respeito pelo outro" (MATURANA, 1998, p. 32).

Quando chamadas para relatar suas histórias de vida, as alunas encontram a possibilidade de reconhecer o poder de suas existências e interação no meio em que estão inseridas. Esta reflexão permite desenvolvimento cognitivo e pessoal a partir desta tomada de conhecimento como seres históricos e passa a considerar todos os espaços como ambientes formativos e que agregam no fazer pedagógico.

Para Josso (2010), estes aspectos são denominados de paradigma do singular plural. Ao lembrar e escrever sua história é possível, ao sujeito que narra, o reconhecimento de fragilidades e quebra de barreiras, olhar pelo singular plural, pois 
é constituído por vários, contudo sua atuação do mundo possui uma singularidade a partir deste plural. Trata-se de uma releitura de mundo, possível através do trabalho de biografizar-se. É o processo de olhar para a história pessoal e particular e ter a oportunidade de ressignificá-la.

As narrativas de cenas marcantes apresentadas neste estudo estão direcionadas para o Ensino Médio, momento peculiar da vida dos estudantes para muitos autores. Diante disso, trazer à tona estas lembranças permite, para este professor em formação, recordar de suas experiências e criar um ambiente de ressignificação. Foi possível perceber o processo de transferência na relação professor e aluno. É muito importante ter o conhecimento dessa transferência, para assim não aprisionar o aluno no saber docente e impossibilitar seu crescimento. O lugar ocupado pelo professor é muito sedutor, pois pode vir a desenvolver nele uma falsa ideia de poder e limitar a ação do aluno.

Caso o professor não tenha consciência da transferência que ocorre na relação com o aluno, ele "alienará totalmente seus alunos aos seus desejos, impedindo a separação e a possibilidade de os alunos lidarem com os conhecimentos da cultura como sujeitos desejantes, passíveis de construir um saber próprio" (GUTIERRA, 2003 , p. 84)

Assim, é essencial que o professor tenha consciência dessa transferência para que o aluno possa existir e não ficar aprisionado em uma imagem construída. $O$ conhecimento jamais deveria ser um lugar de controle.

Guitierra (2003), remetendo-se a Marilena Chauí, aponta como o professor necessita deixar seu lugar vazio, de tal modo que se estabeleça um local para criação do aluno. Quando isso ocorre, "do ponto de vista relacional, esses mestres caracterizam-se por gostar do que fazem, sendo afetivos e receptivos em relação aos alunos, além de acreditarem no potencial deles” (GUTIERRA, 2003, p. 93).

A realização da colcha e a identificação dos momentos charneiras possibilitaram o encontro com um potencial até o momento desconhecido. Reconhecer na história aspectos que influem diretamente na maneira de aprender acaba por permitir o desenvolvimento da autonomia em todas as relações estabelecidas. Tornam o fazer pedagógico ainda mais consciente e presente na intencionalidade. 
Neste viés, precisamos lembrar que somos constituídos de histórias, vivências e experiências que de alguma maneira ficam registradas em nosso corpo, desencadeando sensações e sentimentos tidos como bons e ruins. Tudo isto influencia nossa relação com o aprender, ensinar e pensar como possibilidades de desenvolvimento da autonomia.

\section{Análise dos dados: o lugar do sujeito estético nas narrativas autobiográficas}

Tratar de narrativas na formação inicial de professores requer a criação de espaço para que o sujeito que narra possa compreender o mundo não somente por meio da sua narrativa, mas também através do encontro com a constituição de outros sujeitos. Poeticamente podemos estabelecer um elo da alfabetização com o ato de narrar, como um processo de alfabetização de si. Este processo pode levar o sujeito a perceber sua existência no mundo e com o mundo, promovendo aquilo que Freire chamava de "educação como prática da liberdade". A possibilidade de escutar a história do outro cria este lugar em que o sujeito que narra pode, conforme relata Freire (2005, p. 10)

reencontra-se com os outros e nos outros, companheiros de seu pequeno "círculo de cultura". Encontram-se e reencontram-se todos no mesmo mundo comum e, da coincidência das intenções que o objetivam, ex-surge a comunicação, o diálogo que criticiza e promove os participantes do círculo. Assim, juntos, re-criam criticamente o seu mundo: o que antes os absorvia, agora podem ver ao revés.

Assim que temos contato com as narrativas, percebemos que o ambiente escolar nem sempre permite ou favorece o desenvolvimento total do aluno, de modo a atender suas necessidades no processo. Podemos estabelecer uma analogia ao conceito de holding de Winnicott (1999) para compreendermos a importância do ambiente escolar para uma educação libertadora.

O autor aponta que quando a mulher está adequadamente "amparada" por todo o sistema que a cerca (familiar e social), ela consegue atender às demandas do bebê que acaba de chegar ao mundo. Ele utiliza o conceito de holding, que significa "segurar a criança". Ao atender adequadamente suas necessidades, a mãe possibilita ao bebê uma existência fundamentada na autopercepção. 
Quando existe a possibilidade de as alunas relatarem, classificarem e nomearem suas vivências, seja no âmbito escolar ou pessoal, podemos inferir que alguns aspectos perpassam pelo caminho mencionado acima. Ao dar-se conta da história de vida e dos fatores constitutivos, o professor permite ao aluno que ele também exista e cria condições e suporte para que ele possa existir. Ele cria condições para que o bolding aconteça, pois proporciona o acolhimento na medida certa para que o aluno possa ser quem deseja.

Os aspectos retratados são alguns dos que constituem aquilo que Winnicott (1999) chama de "mãe suficientemente boa", contudo, vale destacar que este papel não significa atender todas as demandas que surgirem. As "falhas" são necessárias justamente para que o bebê possa trazer a consciência sua existência independente da mãe. Da mesma forma, podemos retratar as relações estabelecidas entre professor e aluno; não atender todas as necessidades é o principal caminho para o desenvolvimento da autonomia e autopercepção do aluno.

Quando trabalhamos com as histórias de vida de alunas do curso de Pedagogia, estamos abrindo espaço para consciência desses fatores e, consequentemente, o aprimoramento do trabalho docente. A importância da tomada de consciência do ser é o que abrirá portas para o desenvolvimento de um trabalho mais consciente e, por conseguinte, autônomo e emancipado.

Assim, o dispositivo "Colcha de Retalhos", articula nos sujeitos participantes o que já vimos em Freire (2013), a responsabilidade ética na formação do indivíduo. Nesta perspectiva, ocorre a ampliação de horizontes pela ação docente, promovendo uma leitura de mundo, de tal modo que se promova uma conscientização da sua história. Assim, as amarras percebidas em suas experiências anteriores podem ser ressignificadas, permitindo a estas futuras professoras existir.

Freire (2005) diz que alfabetizar é conscientizar. Logo, ao trazer este conceito para formação de professores podemos associar com a ideia de aprender a ler sua própria história e identificar quais os imbricamentos que ela traz para o seu fazer profissional docente e, consequentemente, quais as possibilidades para uma nova escrita de maneira consciente e autônoma da história.

Este processo de consciência histórica é fundamental para o professor em formação, para não alimentar o que Adorno (2002) destaca como educar para a 
barbárie. Ao trazer estes aspectos à consciência, é possível ao sujeito construir uma nova história e não repetir aspectos do passado que impossibilitaram seu existir de forma autônoma e emancipada. O autor trata a noção de reconhecimento do sujeito constituído socialmente.

Legitimar a existência de si através da narrativa é a validação deste lugar e do objeto de estudo que é a autonomia acontecendo por meio da dimensão estética. Portanto, faz-se necessário compreender que cada um traz uma história e que o sujeito, ao narrar, vivencia uma série de sensações no momento, e estes são fatores fundamentais para o estabelecimento das conexões para construção do conhecimento.

Em consonância, Adorno (2002) também aponta os riscos de uma educação que não favoreça a emancipação do sujeito. Destaca que em muitos momentos a escola está estruturada para condicionar o sujeito a respeitar e seguir as normas, e este é um risco significativo quando falamos da formação de futuros professores. Ao não perceber a existência destes movimentos em sua caminhada formativa, a tendência do professor reproduzir estas histórias é significativamente grande.

Schiller (2002) nos lembra da importância do resgate do sensível no mundo e consequentemente no sujeito. Criar situações que possibilitem o contato com este aspecto permite àquele que narra o desvelar de um novo universo, assim como a possibilidade de ressignificar a história. Assevera que

a natureza humana é "mista", ou seja, que é dotada não apenas de razão, mas de razão e sensibilidade. Sendo assim, permanecerá sempre uma empresa inútil a de quem elevar moralmente - isto é, racionalmente - o homem sem, ao mesmo tempo, cultivar sua sensibilidade (SCHILLER, 2002, p. 13-14).

Ao desconsiderar este lugar corre-se o risco deste futuro professor ser um mero reprodutor de experiências, sem efetivamente ter consciência do lugar ocupa no mundo.

Neste sentido, ao narrar sua história, os participantes têm a possibilidade de trazer suas questões, inquietações e conquista, encontrando a possibilidade de sair da condição do eu e partir para um lugar coletivo e de identificações. Possibilita trabalhar com crenças que constituem o sujeito e com isso encontrar caminhos e estratégias 
para construção de novos saberes e a identificação de recursos passa a ser algo mais tranquilo e motivador.

Todo este processo é possível, pois o sujeito que narra sai da condição de homem racional e passa para condição de sensível. Neste aspecto, Schiller (2002, p. 109) aponta

a passagem (Ubergang) do estado passivo do sentir (Empfindens) para o estado activo do pensar (Denkens) e do querer (Wollens) não acontece portanto de outro modo a não ser mediante um estado intermédio de liberdade estética [...] Não há nenhum outro caminho para tornar racional o homem sensível a não ser fazendo-o antes estético [...] O facto de alguma vez existir uma forma pura para o homem sensível [...] deverá ser previamente possibilitada através da disposição estética do ânimo. [...] Através da disposição estética do ânimo abre-se assim a actividade própria da razão já no campo da sensibilidade, quebra-se o poder da sensação já dentro dos seus próprios limites.

Favorecer o surgimento deste homem estético possibilita, o que para Freire (1996) é um dos grandes desafios na Educação, atuar para que o aluno assuma o papel de sujeito da produção de sua inteligência do mundo, deixando de ser apenas o receptor do que é transferido pelo professor.

Em sua obra $A$ sombra desta mangueira, Freire (2013), fala sobre o "proibido de ser", ou seja, o quanto somos proibidos de ser e vivemos num exílio de nós mesmos. A relevância da participação na metodologia "Colcha de Retalhos" é justamente o resgate do ser, é a possibilidade de um caminho que proporciona a busca deste exílio, olhando para o passado, a fim de ressignificar o presente e assim transformar o futuro a partir de sua história, para então facilitar a construção e percepção de tantas outras.

A tomada de consciência de ser uma pessoa em projeto, assim como fala Freire (2013), permite que novos processos de aprendizagem aconteçam, para principalmente facilitar isto para o outro. Quando um professor assume a postura de que tudo sabe, torna-se enraizado nas relações e consequentemente não viabiliza o crescimento do sujeito.

A "Colcha de Retalhos" permite ao indivíduo esta percepção de ser incompleto, uma vez que o olhar para sua trajetória exige uma reflexão profunda acerca do tipo de aluno que foram e a relação estabelecida com o conhecimento. Este é o momento de identificar quais as amarras serão necessárias romper rumo à educação libertadora efetivamente. 
Freire (2013) fala da importância da curiosidade e a apresenta aliada ao conceito de estética. Diz que para além da postura epistemológica a constituição do espaço escolar é de fundamental importância, pois ele também desperta no indivíduo as mais diversas sensações. Ao serem convidadas a relatar suas experiências educacionais por meio da "Colcha de Retalhos" as alunas deram um start em suas histórias e trouxeram à tona todas estas lembranças, possibilitando, assim, a identificação de aspectos fundamentais da identidade docente.

Compete ao professor e a escola, portanto, criar espaços e condições para que o sujeito possa existir e principalmente dar-se conta de sua existência no e com o mundo. Isso requer uma concepção educacional que:

evidentemente não assim chamada modelagem de pessoas, porque não temos o direito de modelar pessoas a partir do seu exterior, mas também não a mera transmissão de conhecimentos cuja características de coisa morta já foi mais do que destacada, mas a produção de uma consciência verdadeira [...] Isto seria inclusive da maior importância política; sua ideia, se é permitido dizer assim, é uma exigência política. Isto é uma democracia com o dever de não apenas funcionar, mas operar conforme seu conceito demanda pessoas emancipadas (ADORNO, 2002, p. 141-142).

Diante do exposto, fica evidente o papel do dispositivo "Colcha de Retalhos" como um articulador de histórias, não permitindo ao sujeito manter-se no lugar comum, pois, a todo o momento, é chamado para assumir seu lugar no mundo lugar este de sujeito dotado de autonomia e emancipação, de maneira a evitar o conformismo e a uniformização no processo formativo.

Este processo é essencial para contrapor-se à estética da indústria cultural, que, para Adorno (2002), conduz os indivíduos a serem excessivamente práticos e irreflexivos, o que os leva àquilo que denominou de semiformação, e impediria o indivíduo de emancipar-se. $O$ autor critica fortemente a reprodução de conhecimentos e a massificação cultural, que buscam atender interesses que servem à menor parte da população geral, culminando no que Freire (1996) nomeou de Educação Bancária. Um caminho de reverter este quadro, na prática docente, seria a dimensão estética, como uma linha invisível no desenvolvimento da autonomia.

Para Freire (2013), o professor deveria ter como objetivo principal o despertar da consciência estética no aluno, para assim evitar o que chama de "castração da curiosidade epistemológica". Retrata a importância de o indivíduo existir, sendo o espaço escolar o responsável por proporcionar este "nascimento" e o local para a 
prática de leitura de mundo e dos contextos e não somente da leitura das palavras, ir para além das leituras técnicas para favorecer a leitura do mundo, do contexto e desta maneira permitir que o sujeito coloque-se como alguém que atua e não somente compõe o cenário, de maneira a contemplar também a estética, a ética, a moral, a política, a ideologia, o poder, a política, como linhas invisíveis que sustentam a costura do desenvolvimento da autonomia dos sujeitos.

Não ter consciência destes aspectos, pode desvelar um fazer docente implicado na reprodução de toda opressão vivenciada nos tempos da escola. Freire (2005, p. 35) assevera que

o grande problema está em como poderão os oprimidos, que "hospedam" o opressor em si, participar da elaboração, como seres duplos, inautênticos, da pedagogia de sua libertação. Somente na medida em que se descubram "hospedeiros" do opressor poderão contribuir para o partejamento de sua pedagogia libertadora. Enquanto vivam a dualidade na qual ser é parecer e parecer é parecer com o opressor, é impossível fazê-lo.

Ao recordarem as experiências escolares marcantes, destacando principalmente o lugar do docente em sua constituição histórica, ficam evidentes as marcas deixadas neste lugar, sendo este um possível modelo de docência que elas buscam ou não desempenhar. Este seria um momento de reparação histórica destas experiências. Frente a este cenário, o ato de narrar suas histórias pode ser o deflagrador para a tomada de consciência de ser e estar no mundo.

\section{Considerações finais}

Quando os participantes da "Colcha de Retalhos" são convidados a contar e ouvir as histórias, viabiliza-se uma possibilidade de desenvolvimento dos aspectos constituintes de sua identidade como sujeito singular e coletivo, pois ao entrarem em contato com outras histórias há possibilidade para ressignificação de si, considerando formas diferentes ao olhar para o que foi vivenciado. Acaba por ser um momento de revelação do que por muitos anos foi tomado como verdade absoluta, assim com a condição de escolher e compartilhar a experiência há a abertura para ressignificar aquele fato e, consequentemente, sua história.

Durante todo o processo para desenvolvimento da "Colcha de Retalhos", fica evidente como a experiência estética é um núcleo fundante prenhes de aspectos que 
influenciam a tomada de consciência da história do sujeito, além de como ele consegue escolher e tomar decisões do que ou não relatar e trazer à tona. Mobilizam recursos internos para resgatar as experiências vividas, ao elaborar a narrativa escrita e posteriormente transformá-la em uma imagem que possibilita o acesso ao sensível, converte experiências de vida em uma verdadeira obra de arte. Desta forma, o sujeito também consegue se perceber reflexivo por meio da arte de costurar histórias de si e do outro, sendo autor e produtor de arte, constituindo assim uma possibilidade da passagem da consciência estética à consciência epistemológica.

Deste modo, a arte, presente na prática docente como abertura à criatividade dos discentes e docente por meio da confecção da "Colcha de Retalhos", pode ser entendida, como um projeto de conhecimento dos aspectos que constituem o saber, fazer e ser docente. Ao narrar suas histórias e trazê-las à luz da consciência estética, promove-se a reflexão, a consciência epistemológica é uma possibilidade de ampliar a capacidade do sujeito de olhar para sua história de um lugar diferenciado, posicionando-se para seu lugar de sujeito estético no mundo e com o mundo.

\section{Referências}

ADORNO, T. W. Educação e emancipação. 2. ed. Rio de Janeiro: Paz e Terra, 2002.

BERKENBROCK-ROSITO, M. M. Colcha de Retalhos: história de vida e imaginário na formação. Revista do Centro de Educação. Santa Maria, v. 34, n. 3, 2009.

DELORY-MOMBERGER, C. Experiencia y formación: Biografización, biograficidade y Heterobiografia. RMIE, Mexico, v. 19, n. 62. p. 695-710, set. 2014.

DELORY-MOMBERGER, C. A pesquisa biográfica ou a construção compartilhada de um saber singular. Revista Brasileira de Pesquisa (Auto) Biográfica, Salvador, v. 01. p. 133-147, jan./abr. 2016.

FREIRE, P. Pedagogia da autonomia: saberes necessários à prática educativa. São Paulo: Paz e Terra, 1996.

FREIRE, P. Pedagogia do oprimido. 47. ed. Rio de Janeiro: Paz e Terra, 2005.

FREIRE, P. À sombra desta mangueira. 11. ed. Rio de Janeiro: Paz e Terra, 2013.

GADAMER, H. G, et. al. Hermenêtica Filosófica: nas trilhas de Hans-Georg Gadamer. 1. ed. Porto Alegre: EDIPUCRS, 2000.

GUTIERRA, B. C. C. Adolescência, psicanálise e educação: o mestre "possível" de adolescentes. São Paulo: Avercamp, 2003. 
JOSSO, M.-C. As figuras de ligação nos relatos de formação: ligações formadoras, deformadoras e transformadoras de vida. Educação e pesquisa, São Paulo, v. 32, n. 2, p. 373383, maio/ago. 2006.

JOSSO, M.-C. A transformação de si a partir da narração de histórias de vida. Educação, Porto Alegre/RS, n. 3, v. 63, p. 413-438, set./dez. 2007.

JOSSO, M.-C. Caminhar para si. Porto Alegre: EDIPUCRS, 2010.

JOVCHELOVITCH, S.; BAUER, M. Entrevista Narrativa. In: BAUER, M. GASKELL, G. Pesquisa qualitativa com texto, imagem e som. Petrópolis: Vozes, 2002. p. 90-113.

MATURANA, H. Emoções e linguagem na educação e na politica. Belo Horizonte: UFMG, 1998.

MICHAELIS Dicionário Brasileiro da Lingua Portuguesa. Versão online, 2019. Disponível em: <https://michaelis.uol.com.br/moderno-portugues/> Acesso em: 14 out. 2019.

PASSEGI, M. C., et. al. Pesquisa (auto)biográfica: narrativas de si e formação. Acompanhamento $e$ dispositivos de mediação biográfica: memorial de formação, grupos reflexivos e diário de acompanhamento. Curitiba: CRV, 2013. p. 63-79

SANTOS, L. R. Educação Estética e Utopia Política. Lisboa: Colibri, 2009.

SCHILLER, F. A educação estética do homem. São Paulo: Iluminuras, 2002.

SOUZA, J. P. P. “Colcha de Retalhos” como ponte para construção da identidade docente: um estudo no campo da educação estética. Dissertação (Mestrado em Educação) - Universidade Cidade de São Paulo (UNICID), São Paulo, 2019.

TARDIF, M. Saberes docentes e formação profissional. Petrópolis: Vozes, 2002.

WINNICOTT, D. W. O ambiente e os processos de maturação: estudos sobre a teoria do desenvolvimento emocional. Trad. Irineo Constantino Schuch Ortiz. Porto Alegre: Artes Médicas, 1983.

WINNICOTT, D. W. A família e o desenvolvimento individual Trad. Marcelo Brandão Cipolla. São Paulo: Martins Fontes, 1999.

RECEBIDO: $31 / 05 / 2020$

APROVADO: $28 / 07 / 2020$

RECEIVED: 05/31/2020

APPROVED: $07 / 28 / 2020$

RECIBIDO: $31 / 05 / 2020$

APROBRADO: $28 / 07 / 2020$ 